\title{
KNOWLEDGE, AWARENESS, ATTITUDE AND PRACTICE OF DENTAL PRACTITIONERS REGARDING COVID-19 PANDEMIC AND INFECTION CONTROL: A CROSS SECTIONAL STUDY IN KOLKATA METROPOLITAN REGION
}

\author{
Ritwika Bera ${ }^{1}$, Preeti Kalia ${ }^{2}$,Shilpa Hiremath ${ }^{3}$, Deepesh Jaiswal ${ }^{4}$ \\ ${ }^{1}$ Guru Nanak Institute of Dental Sciences and Research, Kolkata, India \\ ${ }^{2}$ Cerebri Classes LLP, Department of Prosthodontics, Kolkata, India \\ ${ }^{3}$ AIMST University, Department of Pediatric Dentistry, Kedah, Malaysia \\ ${ }^{4}$ Department of Dentistry, ESIC-PGIMSR Medical College \& Hospital Joka, Kolkata, India
}

\begin{abstract}
Background. Coronavirus disease 2019 (COVID-19) is a global pandemic with more than 53,973 people affected in West Bengal state of India.

Objectives. The aim of present study was to assess the Knowledge, Attitudes and Practices (KAP) of dental practitioners in Kolkata city, West Bengal, India regarding COVID-2019 pandemic.

Materials and method. Online questionnaire was distributed among dentists across West Bengal city, using a combination of convenience and snowball sampling. The questionnaire had 17 questions: (1) Section A was 'General section' which comprised of socio-demographic and professional details of the subjects; and (2) Section B comprised of 14 questions depicting knowledge, awareness attitude and practice regarding COVID-19. The data collected was subjected to statistical analysis with level of significance at $p=0.05$. The descriptive statistical analysis was done to compute frequency and percentages. Intergroup comparison was determined by Chi-square statistical analysis to determine the level of significance for responses of each question.

Results. Around 70.4\% undergraduates participated in the study. Only 4.3\% showed accurate knowledge with respect to the incubation period of coronavirus. Coughing and sneezing was considered to be the most common mode of transmission. $98.9 \%$ of dentists considered fever to be the characteristic symptom of the disease. Hand washing and alcohol rubs was advocated by $99.5 \%$ of the dentist. Emergency procedures were considered necessary by $90.8 \%$ dentists. $75.1 \%$ of dentists agree that their practice has been affected by the pandemic.

Conclusion. A constant update regarding COVID-19 should be made available to dental health care professionals through webinars, seminars, discussions and articles. Dentists should keep themselves updated and help to fight against this pandemic.
\end{abstract}

Keywords: awareness, knowledge, attitude, practice dentist, COVID-19

\section{INTRODUCTION}

On 30th January 2020, World Health Organization (WHO) declared a global public health emergency against the outbreak of Coronavirus Disease 2019 (COVID-19), and since then has rapidly achieved a pandemic status. This disease with flu-like symptoms was initially observed among people residing in Wuhan, Hubei Province in China [15]. The causative organism responsible for this outbreak is Severe Acute Respiratory Syndrome Coronavirus 2 (SARS-CoV-2) that belongs to the family Coronaviridae of the order Nidovirales.
In a dental setting, as the dentist and their equipment are in close proximity to the patient, the chance of acquiring infection from the micro-droplets of an infected patient is high and there is a risk of cross-transmission. In developing and tourist-friendly countries, there is a boom of dental tourism due to the availability of quality treatment at affordable prices, which attracts patients from all over the world [6]. In the event of an outbreak, the dentist can be the first person to come in contact with an infected person; they can either unknowingly become a carrier and infect others. But by following proper guidelines, they can prevent the possible spread of the disease and save the

Corresponding author: Dr Deepesh Jaiswal, Department of Dentistry, ESIC-PGIMSR Medical College \& Hospital Joka, Kolkata, India -700104, W2CS/20, Flat No 2, Phase 3, Golf Green, Kolkata-700095, India. Phone: +91 8583076769, e-mail: deeppedomds@gmail.com. 
entire community from its disastrous consequences. To combat the transmission of coronavirus infection, dentists should be aware of recent guidelines to be followed for dental set-up and dental health care professionals [5]. Hence, the present study was undertaken with the aim to assess the knowledge, attitudes and practices (KAP) of dental practitioners regarding the COVID-2019 pandemic among the dental practitioners in the Kolkata Metropolis, India.

\section{MATERIALS AND METHOD}

The present study was a descriptive crosssectional (questionnaire) study, conducted from $25^{\text {th }}$ April, 2020 to $20^{\text {th }}$ June, 2020. The study population consisted of dental health professionals who are engaged in practice in Kolkata Metropolitan region. Study subjects were selected using convenience (researchers themselves contacted dentists to participate in the study) and snowball sampling (the participating dentists were asked to forward the questionnaire to their colleagues), so that maximal participation could be ensured. Participation in the study was voluntary and identification information was not collected from the study subjects. Considering potential errors and sample loss, the final sample size was estimated to be 200. In order to pick the study subjects from our sampling frame (list of all practicing dentists), a simple random sampling methodology was used. However, only 187 subjects returned the questionnaire that constituted the final study sample.

\section{Research instrument}

A self-designed questionnaire written in English language was made specifically for the study. The questionnaire was pre-tested for validity and reliability. The reliability of the questionnaire was good (0.84). The questionnaire was divided into two sections: (1) Section A was 'General section' which comprised of socio-demographic and professional details of the subjects (gender, educational status, type of practice etc.); (2) Section B comprised of 14 questions depicting knowledge, awareness and practice regarding COVID-19 (common symptoms, mode of transmission, availability of vaccine, various preventive measures, details of hygiene practices etc.). The questionnaire was circulated to the study subjects via e-mail and WhatsApp (Social Media Application) and not handed over personally because of city 'Lockdown' to prevent Coronavirus spread. The subjects were given one week time to fill the questionnaire and return it.

\section{Statistical analysis}

The data collected was subjected to statistical analysis with level of significance at $p=0.05$, using
IBM SPSS software 20.0. The descriptive statistical analysis was done to compute frequency and percentages. Intergroup comparison was determined by $C h i$ square statistical analysis to determine the level of significance for responses of each question.

\section{RESULTS}

A total of 187 study subjects were included in study, out of which $49.7 \%$ were males and $48.7 \%$ were females. Around $70.43 \%$ participants were dental graduates and $29.56 \%$ were postgraduates. Significantly higher responses were obtained from dentists working in university clinics $(59.5 \%)$, followed by dentists working in public $(9.5 \%)$ and private sectors $(31 \%)$. The demographic data obtained was statistically analysed using Chi-square statistical test and it was found to be statistically significant ( $p$-value $<0.05$ ) for designation and job profile of dental professionals (Table 1).

Section B included 14 questions regarding the knowledge, attitude and practices of dental health professionals related to COVID-19 (Table 2).

\section{Knowledge regarding COVID-19}

A significant difference was observed in response concerning the incubation period of the COVID-19 infections. $64.7 \%$ of the subjects were aware of the fact about 1-14days incubation period of corona virus. $98.9 \%$ of dental professionals considered fever as the characteristic symptoms of COVID-19. $80.6 \%$ of the subjects suggested that COVID-19 may not be associated with any symptoms. $97.3 \%$ of the dental professionals thought that the common mode of transmission of COVID-19 was coughing and sneezing, whereas $89.3 \%$ and $81.3 \%$ of the subjects thought touching contaminated surfaces and hand shaking was more likely to spread the infection respectively.

\section{Attitude regarding COVID-19}

$51.1 \%$ of the subjects assumed that COVID-19 is moderately dangerous, whereas $44.1 \%$ replied that it is extremely dangerous. $95.7 \%$ of the subjects replied that dentist can help to spread awareness of COVID-19. $41.2 \%$ of the subjects thought that hand hygiene and PPE are moderately effective in preventing COVID-19. $99.5 \%$ of dentists assumed that using alcohol based hand rubs and soaps is the best method to prevent spread of COVID-19 infection whereas $17.1 \%$ of the people thought that preventive procedures are unnecessary and may cause panic. $89.1 \%$ dentists thought that dental emergency procedures should be carried out whereas $90.8 \%$ thought that procedures like scaling and polishing should not be carried out. $44.3 \%$ dentists do not want to treat patient's suffering from COVID19. 
Table 1. Distribution of study subjects according to demographic characteristics

\begin{tabular}{|c|c|c|c|c|c|}
\hline \multicolumn{3}{|c|}{ Descriptive data } & \multicolumn{3}{|c|}{ Chi square statistical analysis } \\
\hline Gender $(n=187)$ & No. of response & Percentage & $\mathbf{X}^{2}$ & df & p-value \\
\hline Male & 93 & 49.7 & \multirow{3}{*}{9.501} & 4 & \multirow{3}{*}{0.976} \\
\hline Female & 91 & 48.7 & & & \\
\hline Don't want to specify & 3 & 1.6 & & & \\
\hline \multicolumn{3}{|c|}{ Descriptive data } & \multicolumn{3}{|c|}{ Chi square statistical analysis } \\
\hline Designation $(n=186)$ & No. of response & Percentage & $\mathbf{X}^{2}$ & df & p-value \\
\hline BDS & 131 & 70.43 & \multirow{2}{*}{5.22} & 2 & \multirow{2}{*}{$0.0433^{*}$} \\
\hline MDS & 55 & 29.56 & & & \\
\hline \multicolumn{3}{|c|}{ Descriptive data } & \multicolumn{3}{|c|}{ Chi square statistical analysis } \\
\hline Health sector $(n=168)$ & No. of response & Percentage & $\mathbf{X}^{2}$ & df & p-value \\
\hline University clinics & 100 & 59.5 & \multirow{3}{*}{3.82} & \multirow{3}{*}{3} & \multirow{3}{*}{$0.0013^{*}$} \\
\hline Private sector & 52 & 31 & & & \\
\hline Public sector & 16 & 9.5 & & & \\
\hline
\end{tabular}

$*$ p-value $<0.05$ is significant

Table 2. Response to questionnaire

\begin{tabular}{|c|c|c|c|c|c|}
\hline $\begin{array}{l}\text { Q. What is the incubation } \\
\text { period of corona virus? }\end{array}$ & $\begin{array}{c}\text { No. of response } \\
(\mathrm{n}=187)\end{array}$ & Percentage & $\mathbf{X}^{2}$ & df & p-value \\
\hline 1 TO 14 & 121 & 64.7 & \multirow{4}{*}{17.08} & \multirow{4}{*}{4} & \multirow{4}{*}{$0.019^{*}$} \\
\hline $2 \mathrm{TO} 7$ & 8 & 4.3 & & & \\
\hline 7 TO 14 & 54 & 28.9 & & & \\
\hline 7 TO 21 & 4 & 2.1 & & & \\
\hline $\begin{array}{l}\text { Q. What are the symptoms } \\
\text { of Covid-19 infection? }\end{array}$ & $\begin{array}{c}\text { No. of response } \\
(n=186)\end{array}$ & Percentage & $\mathbf{X}^{2}$ & df & p-value \\
\hline Fever & 184 & 98.9 & \multirow{11}{*}{1.634} & \multirow{11}{*}{11} & \multirow{11}{*}{0.180} \\
\hline Cough & 173 & 93 & & & \\
\hline Shortness of breath & 136 & 73.1 & & & \\
\hline Diarrhoea & 93 & 50 & & & \\
\hline Vomiting & 59 & 31.7 & & & \\
\hline Headache & 113 & 60.8 & & & \\
\hline Sore throat & 168 & 90.3 & & & \\
\hline Runny nose & 48 & 25.8 & & & \\
\hline Loss of taste or smell & 41 & 22 & & & \\
\hline Joint or muscle pain & 78 & 41.9 & & & \\
\hline $\begin{array}{l}\text { May present with no } \\
\text { symptoms }\end{array}$ & 150 & 80.6 & & & \\
\hline $\begin{array}{l}\text { Q. What is the mode of } \\
\text { transmission? }\end{array}$ & $\begin{array}{c}\text { No. of response } \\
(n=187)\end{array}$ & Percentage & $\mathbf{X}^{2}$ & df & p-value \\
\hline Coughing \& sneezing & 182 & 97.3 & \multirow{3}{*}{2.73} & \multirow{3}{*}{3} & \multirow{3}{*}{$0.002 *$} \\
\hline Hand shaking & 152 & 81.3 & & & \\
\hline $\begin{array}{l}\text { Touching surfaces such as } \\
\text { doorknobs }\end{array}$ & 167 & 89.3 & & & \\
\hline Q. Is Covid19 dangerous? & $\begin{array}{c}\text { No. of response } \\
(\mathrm{n}=186)\end{array}$ & Percentage & $\mathbf{X}^{2}$ & df & p-value \\
\hline Extremely dangerous/fatal & 82 & 44.1 & \multirow{3}{*}{9.51} & \multirow{3}{*}{4} & \multirow{3}{*}{$0.050^{*}$} \\
\hline Moderately dangerous & 95 & 51.1 & & & \\
\hline Not A serious health issue & 9 & 4.8 & & & \\
\hline
\end{tabular}




\begin{tabular}{|c|c|c|c|c|c|}
\hline $\begin{array}{l}\text { Q. Is it possible to spread } \\
\text { awareness of Covid19 by } \\
\text { dentists? }\end{array}$ & $\begin{array}{c}\text { No. of response } \\
(n=186)\end{array}$ & Percentage & $\mathbf{X}^{2}$ & df & p-value \\
\hline Yes & 178 & 95.7 & \multirow{3}{*}{5.23} & \multirow{3}{*}{3} & \multirow{3}{*}{0.241} \\
\hline No & 3 & 1.6 & & & \\
\hline Maybe & 5 & 2.7 & & & \\
\hline $\begin{array}{l}\text { Q. How effective are PPE } \\
\text { and hand hygiene in } \\
\text { preventing Covid19? }\end{array}$ & $\begin{array}{c}\text { No. of response } \\
(n=187)\end{array}$ & Percentage & $\mathbf{X}^{2}$ & df & p-value \\
\hline Not required & 0 & 0 & \multirow{5}{*}{12.08} & \multirow{5}{*}{5} & \multirow{5}{*}{$0.020^{*}$} \\
\hline Not effective & 4 & 2.1 & & & \\
\hline Slightly effective & 38 & 20.3 & & & \\
\hline Moderately effective & 77 & 41.2 & & & \\
\hline Extremely effective & 68 & 36.4 & & & \\
\hline $\begin{array}{l}\text { Q. What are the measures } \\
\text { for prevention used by } \\
\text { dentists? }\end{array}$ & $\begin{array}{c}\text { No. of response } \\
(n=187)\end{array}$ & Percentage & $\mathbf{X}^{2}$ & df & p-value \\
\hline $\begin{array}{l}\text { Frequently clean hands by } \\
\text { using alcohol based hand rub } \\
\text { or soap }\end{array}$ & 186 & 99.5 & \multirow{8}{*}{6.72} & \multirow{8}{*}{9} & \multirow{8}{*}{$0.010^{*}$} \\
\hline $\begin{array}{l}\text { Routinely clean surfaces } \\
\text { in contact with known or } \\
\text { suspected patients }\end{array}$ & 178 & 95.2 & & & \\
\hline $\begin{array}{l}\text { Personal protective equipment } \\
\text { (dental goggles, masks and } \\
\text { gloves) }\end{array}$ & 180 & 96.3 & & & \\
\hline $\begin{array}{l}\text { Put face mask on known or } \\
\text { suspected patients }\end{array}$ & 171 & 91.4 & & & \\
\hline $\begin{array}{l}\text { Avoid moving and } \\
\text { transporting patients out of } \\
\text { their area unless necessary }\end{array}$ & 152 & 81.3 & & & \\
\hline $\begin{array}{l}\text { All health member staff wear } \\
\text { protective clothing }\end{array}$ & 182 & 97.3 & & & \\
\hline $\begin{array}{l}\text { Place known or suspected } \\
\text { patients in adequately } \\
\text { ventilated single rooms }\end{array}$ & 154 & 82.4 & & & \\
\hline $\begin{array}{l}\text { Follow proper sterilisation } \\
\text { procedure of instruments } \\
\text { according to who }\end{array}$ & 179 & 95.7 & & & \\
\hline $\begin{array}{l}\text { Proper Disinfection Of Dental } \\
\text { Clinic }\end{array}$ & 185 & 98.9 & & & \\
\hline $\begin{array}{l}\text { Q. What are the procedures } \\
\text { to prevent transmission of } \\
\text { COVID-19 infection? }\end{array}$ & $\begin{array}{l}\text { No. of response } \\
(n=185)\end{array}$ & Percentage & $\mathbf{X}^{2}$ & df & p-value \\
\hline Routine check-ups & 80 & 43.2 & \multirow{7}{*}{9.51} & \multirow{7}{*}{7} & \multirow{7}{*}{0.810} \\
\hline $\begin{array}{l}\text { Endodontic therapy like Root } \\
\text { canal Therapy, filling }\end{array}$ & 157 & 84.9 & & & \\
\hline $\begin{array}{l}\text { Prosthodontic procedure like } \\
\text { construction of RPD,FPD,CD }\end{array}$ & 117 & 63.2 & & & \\
\hline Scaling and polishing & 168 & 90.8 & & & \\
\hline Crown cutting & 143 & 77.3 & & & \\
\hline Minor oral surgical procedures & 88 & 47.6 & & & \\
\hline Emergency procedures & 22 & 11.9 & & & \\
\hline
\end{tabular}




\begin{tabular}{|c|c|c|c|c|c|}
\hline $\begin{array}{l}\text { Q. What are the } \\
\text { Precautionary measures for } \\
\text { patients in clinics? }\end{array}$ & $\begin{array}{c}\text { No. of response } \\
(n=187)\end{array}$ & Percentage & $\mathbf{X}^{2}$ & df & p-value \\
\hline $\begin{array}{l}\text { Make patients maintain social } \\
\text { distancing in waiting area }\end{array}$ & 185 & 98.9 & \multirow{4}{*}{12.58} & \multirow{4}{*}{4} & \multirow{4}{*}{1.310} \\
\hline All patients should wear mask & 184 & 98.4 & & & \\
\hline $\begin{array}{l}\text { Wash hands before getting in } \\
\text { dental chair }\end{array}$ & 179 & 95.7 & & & \\
\hline $\begin{array}{l}\text { Preventive measures are not } \\
\text { necessary, may cause panic }\end{array}$ & 32 & 17.1 & & & \\
\hline $\begin{array}{l}\text { Q. Will you treat a patient } \\
\text { with covid19 infection? }\end{array}$ & $\begin{array}{c}\text { No. of response } \\
(n=174)\end{array}$ & Percentage & $\mathbf{X}^{2}$ & df & p-value \\
\hline Not at all & 77 & 44.3 & \multirow{5}{*}{6.43} & \multirow{5}{*}{5} & \multirow{5}{*}{$0.010^{*}$} \\
\hline In life threatening cases & 22 & 12.6 & & & \\
\hline $\begin{array}{l}\text { Yes, with proper PPE kits and } \\
\text { strict preventive measures }\end{array}$ & 42 & 24.1 & & & \\
\hline Sufficient routine measures & 24 & 13.8 & & & \\
\hline Without proper PPE & 9 & 5.2 & & & \\
\hline $\begin{array}{l}\text { Q. Do you include travel } \\
\text { history while recording } \\
\text { patient history? }\end{array}$ & $\begin{array}{c}\text { No. of response } \\
(\mathbf{n}=\mathbf{1 8 3})\end{array}$ & Percentage & $\mathbf{X}^{2}$ & df & p-value \\
\hline Yes & 169 & 92.3 & \multirow{3}{*}{1.08} & \multirow{3}{*}{3} & \multirow{3}{*}{$0.0010^{*}$} \\
\hline No & 6 & 3.3 & & & \\
\hline Maybe & 8 & 4.4 & & & \\
\hline $\begin{array}{l}\text { Q. Do you discuss the risks } \\
\text { of covid19 with patients? }\end{array}$ & $\begin{array}{c}\text { No. of response } \\
(n=184)\end{array}$ & Percentage & $\mathbf{X}^{2}$ & df & p-value \\
\hline Yes & 152 & 82.6 & \multirow{3}{*}{14.08} & \multirow{3}{*}{3} & \multirow{3}{*}{$0.0510^{*}$} \\
\hline No & 13 & 7.1 & & & \\
\hline Maybe & 19 & 10.3 & & & \\
\hline $\begin{array}{l}\text { Q. Do you discuss preventive } \\
\text { measures against covid19 } \\
\text { with patients? }\end{array}$ & $\begin{array}{c}\text { No. of response } \\
(\mathrm{n}=182)\end{array}$ & Percentage & $\mathbf{X}^{2}$ & df & p-value \\
\hline Yes & 160 & 87.9 & \multirow{3}{*}{7.18} & \multirow{3}{*}{3} & \multirow{3}{*}{$0.004^{*}$} \\
\hline No & 11 & 6 & & & \\
\hline Maybe & 11 & 6 & & & \\
\hline $\begin{array}{l}\text { Q. Has covid19 affected your } \\
\text { professional life in a clinical } \\
\text { set-up? }\end{array}$ & $\begin{array}{c}\text { No. of response } \\
(\mathrm{n}=181)\end{array}$ & Percentage & $\mathbf{X}^{2}$ & df & p-value \\
\hline Yes & 136 & 75.1 & \multirow{3}{*}{16.51} & \multirow{3}{*}{3} & \multirow{3}{*}{$0.0001^{*}$} \\
\hline No & 25 & 13.8 & & & \\
\hline Maybe & 20 & 11 & & & \\
\hline
\end{tabular}

\section{Practice regarding COVID-19}

$98.9 \%$ of dentists thought that patients should maintain proper social distancing in the waiting room and $98.4 \%$ of the study subjects thought that facial masks on patients are mandatory. $95.7 \%$ of dentists revealed that patients should wash their hands before going in for dental treatment. $99.3 \%$ of dentists record travel history of patients. $82.6 \%$ dental practitioners discussed the risk associated with COVID-19 and dental treatment with the patients and $87.9 \%$ discuss the preventive measures of COVID-19 with patients. $75.1 \%$ dentists have noticed an effect in their professional life in a clinical set up due to COVID-19.

All the responses obtained for questions regarding KAP of dental health professionals for COVID-19 pandemic were statistically analysed. It was found that responses to all questions were statistically significant (p-value $<0.05$ ), except related to symptoms of COVID-19, question regarding spreading awareness of infection, procedures used to prevent disease transmission, and precautionary measures taken for patients. 


\section{DISCUSSION}

The purpose of this study was to assess the awareness, knowledge, attitude and practice of dental practitioners in the Kolkata metropolitan region in regard to COVID-19 infection. Kolkata is a densely populated region in West Bengal and currently has a total number of 53,973 COVID-19 cases till $24^{\text {th }}$ July, with a total number of active cases are being 19,154 (+308) [20]. Hence, it becomes imperative that the dental practitioners stay aware of the recent guidelines published by WHO and DCI regarding this crisis. The transmission of COVID-19 poses a risk for people who come in close contact with an infected individual, and the risk is greater among those who are in close proximity to or work near the patient, i.e., relatives and healthcare workers. The distance between the working field and the dentist is approx. $35-40 \mathrm{~cm}$, and certain procedures can be very time-consuming, which puts the dentist at a higher risk of contracting COVID-19 [17 ].

According to Lauer et al. [12] the median incubation period from infection with SARS COV2 to onset of symptoms is approximately 5 days. According to Backer et al. [1] incubation period is 3-6 days after exposure with an upper conservative limit of 11 days. In the present study $64.7 \%$ of dentists conveyed that the incubation period of COVID-19 is $1-14$ days, whereas only $4.3 \%$ of the respondents were aware of the more recent updates on the incubation period of 5 days by American College of Cardiology. Researchers estimated that people who get infected with coronavirus can spread it to others, 2 to 3 days before symptoms start and are most contagious 1 to 2 days before they feel sick [2, 10, 19]. Hence, it becomes critical for clinicians to have an accurate idea about the incubation period of COVID-19 to prevent transmission in the dental clinic.

The common symptoms of COVID-19 were correctly identified as fever, cough, sore throat etc. $[3,4]$. In our study, $98.9 \%, 93 \%$ and $90.3 \%$ of the responders said fever, cough and sore throat as the prime signs of corona virus infection. The response rate was higher as compared to the findings in a study by Gambhir et al. [18]. Recent research indicated that gastrointestinal symptoms like diarrhea and vomiting are also associated with COVID-19 [9]. Unfortunately in our study, only $50 \%$ and $31.7 \%$ of the subjects were aware of diarrhea and vomiting respectively as a symptom of COVID-19. Newer symptoms like anosmia and myalgia have also been associated with this infection [13]. However, only $25.8 \%$ knew about myalgia and $22 \%$ knew about anosmia in our study. $80.6 \%$ of the subjects said that COVID-19 may not present with any symptoms.
The data obtained in the study indicated insufficient information regarding the recent symptoms of corona virus among the dentists in Kolkata. The dentist may end up treating asymptomatic patients inadvertently leading to the spread of the disease which should be addressed immediately and care should be taken to sensitise the dentists.

In the present study, $92.3 \%$ of the dentists reported including the travel history while taking consent of the patient which is important in a timely diagnosis, this could prevent further propagation of infection. 95.7\% dentists agreed that they could help spread awareness regarding the disease and $99.5 \%$ of dentists think that maintaining proper hand hygiene is a necessary step. As per the Geo Sentinel surveillance survey [14], $11 \%$ of the respiratory tract infections were reported among the travellers returning to their country of residence, and PPE can provide protection as well as reduce the risk of any nosocomial infections and cross transmission in the dental setting [7, 14]. This collaborated with the study conducted Liu et al. [16]. Hence proper usage of PPE is mandatory $[8,11]$ and $97.3 \%$ of our study subjects are of the same opinion.

A total of $44.1 \%$ dentists responded that COVID-19 was fatal in nature and this could be attributed to the fact that the mortality associated with any new outbreak (although lower in the case of COVID-19) instils a fear of the unknown among people. However $4.8 \%$ of the dentists think it's not a serious issue at all. $17.1 \%$ dentists claim that precautionary measures can cause unnecessary panic and they tend to downplay the severity of the situation. Our study revealed that professional life and financial condition in a clinical set up has been affected for $75.1 \%$ of the dentists in the study.

Thus, present study showed that dental professionals play an imperative role in breaking the transmission chain by using the appropriate procedures to decrease the diffusion of viral agents, or by controlling the unwanted spread of infectious disease, using the advised safety guidelines.

\section{Limitations of the study:}

The study is conducted using limited sample size. More studies should be conducted with large sample and involving dental professionals from various regions of India.

The present study was a cross-sectional study. Thus self-selection bias can occur due to the sampling technique used.

We kept minimum number of questions in our survey to keep it simple and to improve the response rate of participants. 


\section{CONCLUSION}

The present study concluded that the knowledge of dentists with regard to the pathogenesis, mode of transmission and clinical features was not updated. Therefore a periodic update among dentist regarding the pathogenesis, mode of transmission and clinical manifestations of the disease should be made available through WEBINARS and articles.

It is the duty of the dentist to be aware and provide assistance in the war against COVID-19. The paradox of the situation is that dentists are unable to treat patients without proof of a negative test result yet is not in a position to administer the tests themselves.

The government should make measures to let the dentists test for COVID-19 by collecting swabs from the patients in the dental clinic to combat this disease.

\section{Conflict of interest}

None declared.

\section{REFERENCES}

1. Backer JA, Klinkenberg D, Wallinga J.: Incubation period of 2019 novel coronavirus (2019-nCoV) infections among travellers from Wuhan, China, 20-28 January 2020. Euro Surveill. 2020;25(5):2000062.

2. Chan JFW, Yuan S, Kok KH, Wang KKT, Chu H, Yang $J$, et al.: A familial cluster of pneumonia associated with the 2019 novel coronavirus indicating person-toperson transmission: a study of a family cluster. Lancet 2020;395:514-23. Doi: 10.1016/S0140-6736(20)30154-9.

3. Coronavirus disease 2019 (COVID-2019). Centers for Disease Control and Prevention. https://www.cdc.gov/ coronavirus/2019-ncov/index.html. Accessed June 26, 2020.

4. Coronavirus disease (COVID-19) outbreak. World Health Organization. https://www.who.int/emergencies/ diseases/novel-coronavirus-2019. Accessed June 26, 2020.

5. Country \& Technical Guidance - Coronavirus disease (COVID-19). Available on: https://www.who. int/emergencies/diseases/novel-coronavirus-2019/ technical-guidance-publications. Accessed July 26, 2020

6. Dham KA, Pattha B, Singla A, Gupta R., Niraj LK, Ali I., Kumar JK, Prasad M.: Global Tourist Guide to Oral Care - A Systematic Review. J Clin Diagn Res. 2016;10(9):ZE0-4. Doi: 10.7860/JCDR/2016/19438.8408

7. Duong TN, Waldman SE.: Importance of a travel history in evaluation of respiratory infections. Curr Emerg Hosp Med Rep. 2016;4(3):141-152.

8. Fotedar S, Sharma KR, Bhardwaj V, Fotedar V:: Precautions in dentistry against swine flu. SRM J Res Dent Sci. 2013;4(4):161-3.
9. Han C, Duan C, Zhang S, et al.: Digestive Symptoms in COVID-19 Patients With Mild Disease Severity: Clinical Presentation, Stool Viral RNA Testing, and Outcomes. Am J Gastroenterol. 2020;115(6):916-923; doi: 10.14309/ajg.0000000000000664.

10. He X, Lau EHY, Wu P, Deng X, Wang J, Hao X et al.: Temporal dynamics in viral shedding and transmissibility of COVID-19. Nat Med. 2020;26(5):672-675.

11. Kamate SK, Sharma S, Thakar S, Srivastava D, Sengupta K, Hadi AJ, Chaudhary A., Joshi R., Dhanker $K$.: Assessing Knowledge, Attitudes and Practices of dental practitioners regarding the COVID-19 pandemic: A multinational study. Dent Med Probl. 2020;57(1):1117.

12.Lauer SA, Grantz $K H, B i Q$, et al.: The Incubation Period of Coronavirus Disease 2019 (COVID-19) From Publicly Reported Confirmed Cases: Estimation and Application. Ann Intern Med. 2020;172(9):577-582.

13.Lechien JR, Chiesa-Estomba CM, De Siati DR, et al.: Olfactory and gustatory dysfunctions as a clinical presentation of mild-to-moderate forms of the coronavirus disease (COVID-19): a multicenter European study. Eur Arch Otorhinolaryngol. 2020;277(8):2251-2261.

14.Leder K, Torresi J, Libman MD, et al.: GeoSentinel surveillance of illness in returned travelers, 20072011. Ann Intern Med. 2013;158(6):456-468. doi: 10.7326/0003-4819-158-6-201303190-00005.

15. Li Y, Xia L.: Coronavirus Disease 2019 (COVID-19): Role of Chest CT in Diagnosis and Management. AJR Am J Roentgenol. 2020;214(6):1280-6.

16. Liu M, Cheng $S, X u K$, Yang Y, Zhu Q, Zhang H, et al.: Use of personal protective equipment against coronavirus disease 2019 by healthcare professionals in Wuhan, China: cross sectional study. BMJ 2020;369:16.; DOI: https://doi.org/10.1136/bmj.m2195.

17. Pîrvu C, Pătraşcu I, Pîrvu D, Ionescu C.: The dentist's operating posture - ergonomic aspects. J Med Life. 2014;7(2):177-182.

18. Singh Gambhir R, Singh Dhaliwal J, Aggarwal A, Anand S, Anand V, Kaur Bhangu A:: Covid-19: a survey on knowledge, awareness and hygiene practices among dental health professionals in an Indian scenario. Rocz Panstw Zakl Hig 2020;71(2):223-229. doi:10.32394/ rpzh.2020.0115.

19. Thomas MV, Jarboe G, Frazer RQ.: Infection Control in the Dental Office. Dent. Clin. North Am. 2008;52:60928.

20. West Bengal Covid-19 Health Bulletin. Available on: https://www.wbhealth.gov.in/pages/corona/bulletin. Accessed July 26, 2020

Received: 05.08 .2020

Accepted: 22.12 .2020 